\title{
圧縮コイルばねの信頼性設計* \\ Reliability Design of Helical Compression Spring
}

陳 立**

\section{Li CHEN}

信頼性設計は新しい技術分野である。ばね工業では信頼性工学の適用はまだ信頼性試験の段 階に止まっていて, 信頼性設計についての研究資料は少ない。本研究では長年の信頼性研究に もとづいて，応力分布と強度分布の干渉理論を圧縮コイルばねに応用し，その信頼性設計公式 を導いた。特に，ショットピーニングやホットセッチングなどの製造工程が，製品の寿命に及 ぼす影響を設計パラメタとしてはじめて導入した。また，設計の信頼性と製品の材料強度及び 製造手段レベルとの関係を定式化し，ばねの信頼性設計の理論体系の基礎を確立した。

Reliability design is a developing domain of the science and technology. At present, the reliability engineering in spring manufacture is only on the stage of reliability testing and there are few documents concerning research in this field. After many years' reliability study, the author has deduced the reliability design formula for helical compression springs by the intervene theory of stress-strength distribution. This is the first time that the shot-peening and warm setting are introduced in the design parameters affecting the life of products. The author has also specified the relations between reliability and material strength of the products and the manufacturing process level. It will establish the basis of the system of spring reliability design theory.

\section{1. 緒 言}

信頼性工学の理論的基礎は確率論と数理統計学であ る。それらはシステム工学, 環境工学, 価値工学, 品 質管理, コンピューター技術などと密切な関係にある 科学である1)。

信頼性工学は 1950 年代から航空, 宇宙, 電子技術の 分野で発展してきた。その後, 民生工業にも次第に利 用が拡がり, 自動車, トラクター, オートバイ, エン ジン, 油圧ポンプなどの製造工場で, 信頼性工学技術 の応用が始まったが, その部品, 例えば, ばねにも信 頼性が要求される。

しかし,ばねの設計に対しては信頼性工学の応用が あまり進んでいない。そのおもな原因は以下の点にあ る。(1)完全かつ正確なばねの信頼性設計の理論体系が ない。(2)古典的な機械設計法が習慣になっている。(3) 信頼性設計には十分な統計的設計データが必要である。 しかし, 信頼性標準及び設計レベルの評価と品質保証 制度を制定し, 信頼性試験を行い, 信頼性のデータべ 一スを確立するには，長い時間がかかる。

製品の信頼性は設計で決定され, 適当な製造工程, 完全に整った品質管理, 優良なサービスなどの信頼性
工学的方法によって保証される。製品設計の信頼性が 低ければ，いかにすぐれた製造方法でも，高い信頼性 を有する製品を製造出来ない。したがって, 製造の前 に必ず信頼性設計を行い信頼性の低い製品を無くさな ければならない。

ばね工業では信頼性の研究はまだ信頼性試験の段階 に止まっていて, 信頼性設計についての研究資料は少 ない。本研究では著者の長年の信頼性研究にもとづい て, 手はじめに, 圧縮コイルばねの信頼性設計の理論 体系を確立する。

\section{2. 圧縮コイルばねの信頼性設計}

\section{1 ばね設計における基本的要求}

（1）強度に対する要求を満足させるように取ったせ ん断応力が，機能喪失を引きおこさない。

（2）ばね定数を満足させるばねのたわみが，規定許 容差を越えない。

（3）幾何学的寸法を満足する。

\section{2 コイルばねのおもな機能衰失形式}

(1) 疲労破壊

(2) ばね定数の減少(へたり)

原稿受付日 1993 年 8 月 23 日

* サンコール(株) 小村敞一氏の紹介による海外からの直接投稿

**中国弾簧廠 (China Spring Factory)

上海中星汽車愻架件有限公司 (Shanghai Chisca Auto Suspension Components Co., Ltd.) 


\section{3 ばねの信頼性設計手順}

一定応力振幅下でばねが破損する繰返し数の分布曲 線は対数正規分布であり, 応力分布とせん断疲れ強度 分布も正規分布であると仮定する ${ }^{23)}$ 。

a ) 応力分布 $\tau_{\text {max }}\left(\bar{\tau}, \xi_{\tau}\right)$ を決定する

$\tau_{\text {max }}\left(\bar{\tau}, \xi_{\tau}\right)$ は $\left(\tau_{\text {max }}\right.$ : 最大せん断応力, $\bar{\tau}$ : 平均 值, $\xi_{\tau}$ : 標準偏差)の正規分布に従う。

b ) 世ん断瘦れ強さ分布 $\mathrm{S}_{\mathrm{m}}\left(\overline{\mathrm{S}_{\mathrm{m}}}, \xi \mathrm{S}_{\mathrm{m}}\right)$ を決定する $\mathrm{S}_{\mathrm{m}}\left(\overline{\mathrm{S}_{\mathrm{m}}}, \xi \mathrm{S}_{\mathrm{m}}\right)$ は平均值 $\overline{\mathrm{S}_{\mathrm{m}}}$, 標準偏差 $\xi \mathrm{S}_{\mathrm{m}}$ の正規分 布に従う。

c）強度分布と応力分布が重なる確率が確定したら， 信頼度 $\mathrm{R}$ を計算する。

\section{4 コイルばねの信頼性設計法}

\section{4 .1 応力分布の決定}

（1）おもな变数が軸方向力 $\mathrm{P}$ の場合

コイルばねの内側に生ずる最大応力 $\tau_{\text {max }}$ はつぎ

のようになる。

$\tau=\mathrm{K}(8 \mathrm{PD}) / \pi \mathrm{d}^{3}$

ここでは $\mathrm{K} ワ ー ル の$ 応力修正係数

$\mathrm{K}=(4 \mathrm{D}-\mathrm{d}) /(4 \mathrm{D}-4 \mathrm{~d})+0.615 \mathrm{~d} / \mathrm{D}$

である。

各量の平均値を量記号に『一』を付して示せば, せん断応力の平均値は

$$
\begin{aligned}
\bar{\tau}= & {[(4 \overline{\mathrm{D}}-\overline{\mathrm{d}}) /(4 \overline{\mathrm{D}}-4 \overline{\mathrm{d}})} \\
& +0.615 \overline{\mathrm{d}} / \overline{\mathrm{D}}](8 \overline{\mathrm{PD}}) / \pi \overline{\mathrm{d}}^{3}
\end{aligned}
$$

となる。

また，せん断応力の標準偏差は正確には

$$
\xi_{\tau}=\left[(\partial \tau / \partial \mathrm{d})^{2} \xi_{\mathrm{d}}^{2}+(\partial \tau / \partial \mathrm{D})^{2} \boldsymbol{\xi}_{\mathrm{D}}^{2}\right.
$$$$
\left.+(\partial \tau / \partial \mathrm{P})^{2} \xi_{\mathrm{P}}^{2}\right]
$$

で与えられるが，その概略値は

$\xi_{\tau}=(0.015 \sim 0.05) \bar{\tau}$

となる。ここで，記号は各々

$\mathrm{P} ：$ 軸方向圧縮力

$\mathrm{D}$ ：コイル平均径

$\mathrm{d}$ ：線径

$\xi_{\mathrm{P}}$ : 軸方向圧縮力の標準偏差

$\xi_{\mathrm{D}}:$ コイル平均径の標準偏差

$\xi_{\mathrm{d}}:$ 線径の標準偏差

を表わし，

$\xi_{\mathrm{P}} ， \boldsymbol{\xi}_{\mathrm{D}} ， \boldsymbol{\xi}_{\mathrm{d}}$ は許容差範囲の $1 / 6$ を取るものとす る。

例 1

$$
\begin{aligned}
\mathrm{d} & =\Phi 2 \pm 0.02 \\
\boldsymbol{\xi}_{\mathrm{d}} & =[+0.02-(-0.02)] / 6=0.0066
\end{aligned}
$$

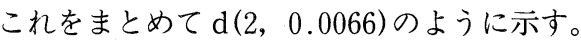

また, $\partial \tau / \partial \mathrm{d}=\partial / \partial \mathrm{d}[\{(4 \mathrm{D}-\mathrm{d}) /(4 \mathrm{D}-4 \mathrm{~d})$

$$
\left.+0.615 \mathrm{~d} / \mathrm{D}\} \times 8 \mathrm{PD} / \pi \mathrm{d}^{3}\right] \quad \cdots(6)
$$

$\therefore \partial \tau / \partial \mathrm{d} \approx 8 \overline{\mathrm{PD}}\left[12 \overline{\mathrm{D}} \overline{\mathrm{d}} /(4 \overline{\mathrm{D}}-4 \overline{\mathrm{d}})^{2}\right.$

$$
-3(4 \overline{\mathrm{D}}-\overline{\mathrm{d}}) /(4 \overline{\mathrm{D}}-4 \overline{\mathrm{d}})-1.845 \overline{\mathrm{d}} / \overline{\mathrm{D}}] / \pi \overline{\mathrm{d}}^{4}
$$

おなじく,

$$
\begin{aligned}
\partial \tau / \partial \mathrm{D} \approx & 8 \overline{\mathrm{P}}\left[-12 \overline{\mathrm{D}} \overline{\mathrm{d}} /(4 \overline{\mathrm{D}}-4 \overline{\mathrm{d}})^{2}\right. \\
& +(4 \overline{\mathrm{D}}-\overline{\mathrm{d}}) /(4 \overline{\mathrm{D}}-4 \overline{\mathrm{d}})] / \pi \mathrm{d}^{3} \\
\partial \tau / \partial \mathrm{P} \approx & 8 \overline{\mathrm{D}}[4 \overline{\mathrm{D}}-\overline{\mathrm{d}}) /(4 \overline{\mathrm{D}}-4 \overline{\mathrm{d}}) \\
& +0.615 \overline{\mathrm{d}} / \overline{\mathrm{D}}] / \pi \overline{\mathrm{d}}^{3} \ldots \ldots \ldots \ldots \ldots . . . . . . . .
\end{aligned}
$$

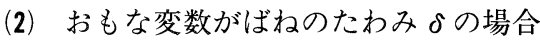

$\mathrm{P}=k \delta$ の,$k$ 及び $\delta$ はそれぞれ

$\delta=8 \mathrm{PD}^{3} \mathrm{n} / \mathrm{d}^{4} \mathrm{G}$

$\mathrm{P}=\left(\mathrm{d}^{4} \mathrm{G} / 8 \mathrm{D}^{3} \mathrm{n}\right) \delta$

$k=\mathrm{d}^{4} \mathrm{G} / 8 \mathrm{D}^{3} \mathrm{n}$

である。

式中, $\mathrm{G}$ : 横弾性係数

$$
\begin{aligned}
& \mathrm{n}: \text { 有効巻数 } \\
& k: \text { ばね定数 } \\
\therefore \tau= & {\left[\mathrm{KdG} / \pi \mathrm{D}^{2} \mathrm{n}\right] \delta } \\
= & \mathrm{dG} \delta[(4 \mathrm{D}-\mathrm{d}) /(4 \mathrm{D}-4 \mathrm{~d})+0.615 / \mathrm{D}] / \pi \mathrm{D}^{2} \mathrm{n}
\end{aligned}
$$

せん断応力の平均値：

$\bar{\tau}=\overline{\mathrm{dG} \delta}[(4 \overline{\mathrm{D}}-\overline{\mathrm{d}}) /(4 \overline{\mathrm{D}}-4 \overline{\mathrm{d}})+0.615 / \overline{\mathrm{D}}] / \pi \overline{\mathrm{D}}^{2} \overline{\mathrm{n}} \quad$ (14) せん断応力の標準偏差 :

$$
\begin{aligned}
\xi_{\tau}= & {\left[(\partial \tau / \partial \mathrm{d})^{2} \xi_{\mathrm{d}}^{2}+(\partial \tau / \partial \mathrm{D})^{2} \xi_{\mathrm{D}}^{2}\right.} \\
& +(\partial \tau / \partial \mathrm{G})^{2} \xi_{\mathrm{G}}^{2}+(\partial \tau / \partial \delta)^{2} \xi^{2} \\
& \left.+(\partial \tau / \partial \mathrm{n})^{2} \xi_{\mathrm{n}}^{2}\right]^{1 / 2}
\end{aligned}
$$

式中 : $\boldsymbol{\xi}_{\mathrm{G}}$ : 横弾性係数の標準偏差

$$
\begin{aligned}
& \xi_{\delta}: \text { たわみの標準偏差 } \\
& \xi_{\mathrm{n}}: \text { 有効巻数の標準偏差 }
\end{aligned}
$$$$
\xi_{\mathrm{G}} \approx 0.02 \overline{\mathrm{G}}
$$

$\xi_{\delta}, \quad \xi_{n}$ は許容差範囲の $1 / 6$ を取るものとする。

$\therefore \partial \tau / \partial \mathrm{d} \approx \overline{\mathrm{G}} \bar{\delta}\left[12 \overline{\mathrm{D}} \overline{\mathrm{d}} /(4 \overline{\mathrm{D}}-4 \overline{\mathrm{d}})^{2}\right.$

$$
\begin{aligned}
& +(4 \overline{\mathrm{D}}-\overline{\mathrm{d}}) /(4 \overline{\mathrm{D}}-4 \overline{\mathrm{d}})+0.615 \overline{\mathrm{d}} / \overline{\mathrm{D}}] / \pi \overline{\mathrm{D}}^{2} \overline{\mathrm{n}}(17) \\
& \partial \tau / \partial \mathrm{D} \approx-4 \overline{\mathrm{dG}} \bar{\delta}\left[\left(8 \overline{\mathrm{D}}^{2}-7 \overline{\mathrm{dD}}\right.\right. \\
& \left.\left.+2 \overline{\mathrm{d}^{2}}\right) /(4 \overline{\mathrm{D}}-4 \overline{\mathrm{d}})^{2}+0.461 \overline{\mathrm{d}} / \overline{\mathrm{D}}\right] / \pi \overline{\mathrm{n}} \overline{\mathrm{D}}^{3} \ldots \ldots .(18) \\
& \partial \tau / \partial \mathrm{G} \approx \overline{\mathrm{d} \delta}[4(\overline{\mathrm{D}}-\overline{\mathrm{d}}) /(4 \overline{\mathrm{D}}-4 \overline{\mathrm{d}}) \\
& +0.615 \overline{\mathrm{d}} / \overline{\mathrm{D}}] / \pi \overline{\mathrm{D}}^{2} \overline{\mathrm{n}} \\
& \partial \tau / \partial \delta \approx \overline{\mathrm{dG}}[(4 \overline{\mathrm{D}}-\overline{\mathrm{d}}) /(4 \overline{\mathrm{D}}-4 \overline{\mathrm{d}}) \\
& +0.615 \overline{\mathrm{d}} / \overline{\mathrm{D}}] / \pi \overline{\mathrm{D}^{2} \mathrm{n}} \\
& \partial \tau / \partial \mathrm{n} \approx-\overline{\mathrm{dD} \delta}[(4 \overline{\mathrm{D}}-\overline{\mathrm{d}}) /(4 \overline{\mathrm{D}}-4 \overline{\mathrm{d}}) \\
& +0.615 \overline{\mathrm{d}} / \overline{\mathrm{D}}] / \pi \overline{\mathrm{D}}^{2} \overline{\mathrm{n}}
\end{aligned}
$$

\section{4 .2 強度分布の決定}

ばねの両振り疲れ強さ分布一繰返し数線図を図 1 に 示す。

例えば, $\mathrm{N}=10^{3}$ の, 疲れ強さ分布は $\mathrm{S}_{3}\left(\overline{\mathrm{S}_{3}}, \xi \mathrm{S}_{3}\right)$ で示 され, $\overline{\mathrm{S}_{3}}$ は次式で与えられる。

$$
\begin{aligned}
& \overline{\mathrm{S}_{3}}=\beta \overline{\sigma_{\mathrm{b}}} \\
& \mathrm{C} \leq 4 \text { なら } \quad \beta \sim \mathrm{N}(0.72,0.02) \\
& 4<\mathrm{C} \leq 6 \text { なら } \quad \beta \sim \mathrm{N}(0.63,0.02) \\
& \mathrm{C}>6 \text { なら } \quad \beta \sim \mathrm{N}(0.54,0.02)
\end{aligned}
$$


$\beta$ は疲れ強さ係数で, ばね指数 $\mathrm{C}=\mathrm{D} / \mathrm{d}$ により変化し, $\beta \sim \mathrm{N}(0.72,0.02)$ は $\beta$ の平均值 0.72 , 標準偏差 0.02 の正規分布に従うことを意味する。

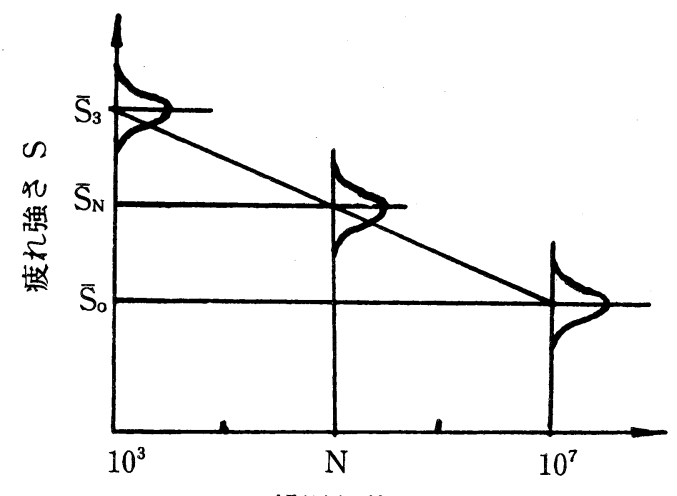

繰返し数 $\mathrm{N}$

図 1 両振り疲れ強さ分布一繰返し数線図

一方, 疲れ強さの標準偏差は次式で与えられる。

$\xi_{53}=\left[\bar{\sigma}_{\mathrm{b}}^{2} \xi_{\beta}^{2}+\bar{\beta}^{2} \xi_{\sigma \mathrm{b}}^{2}\right]^{1 / 2} \ldots \ldots \ldots \ldots \ldots \ldots \ldots \ldots \ldots \ldots(23)$

式中， $\bar{\sigma}_{\mathrm{b}}$ は引張強さの平均值で，その標準偏差は

$\xi_{\sigma \mathrm{b}} \approx 0.05 \bar{\sigma}_{\mathrm{b}}$

..(24)

変動係数は $\mathrm{V}_{\mathrm{S} 3}=\xi_{\mathrm{s} 3} / \overline{\mathrm{S}}_{3}$ (25)

で与えられる。

また, $\mathrm{N}=10^{7}$ に対する,ばねの耐久限度分布は $\mathrm{S}_{0}\left(\overline{\mathrm{S}}_{0}\right.$, $\xi_{\text {so }}$ )で示される。但し,

$\overline{\mathrm{S}}_{0}=0.3 \mathrm{~K}_{\mathrm{f}} \cdot \mathrm{K}_{\mathrm{e}} \cdot \overline{\sigma_{\mathrm{b}}}$ (26)

式中, $\mathrm{K}_{\mathrm{f}}$ は応力集中係数 (図 2 参照)

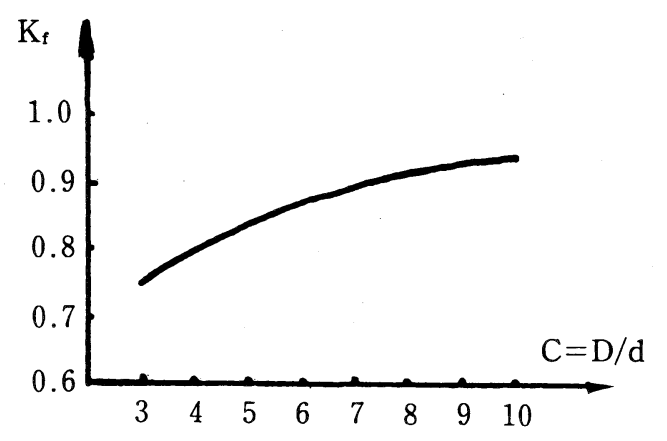

図 $2 \mathrm{~K}_{\mathrm{f}}$ とばね指数の関係

$\mathrm{K}_{\mathrm{e}}$ は工程係数 (加工工程による材料の強化係数)

$$
\mathrm{K}_{\mathrm{e}}=1+\mathrm{K}_{\mathrm{P}}+\mathrm{K}_{\mathrm{h}}
$$

式中,

$\mathrm{K}_{\mathrm{P}}$ はショットピーニングによる強化係数で

$$
\mathrm{K}_{\mathrm{P}}=0.2
$$

同様に， $\mathrm{K}_{\mathrm{h}}$ はホットセッチングによる強化係数で

$$
\mathrm{K}_{\mathrm{h}}=0.2
$$

とみなす。また，その標準偏差は

$$
\xi_{\mathrm{s} 0}=0.05 \overline{\mathrm{S}}_{0}
$$

$$
\mathrm{V}_{\mathrm{s} 0}=\xi_{\mathrm{s} 0} / \overline{\mathrm{S}}_{0}=0.05
$$
で与えられる。

繰返し数, $10^{3}<\mathrm{N}<10^{7}$ 回のとき, 変動係数 $\mathrm{Vs}_{\mathrm{S}}$ 形 $\mathrm{s}$ にたいし線形に変化すると仮定すると,

$$
\mathrm{V} \mathrm{s}=\mathrm{V}_{\mathrm{s} 3}+(1 \mathrm{gN}-3)\left(\mathrm{V}_{\mathrm{s} 0}-\mathrm{V}_{\mathrm{s} 3}\right) / 4
$$

同様に任意な寿命 $\mathrm{N}$ に対し, せん断疲れ強さ $\mathrm{S}_{\mathrm{N}}$ が線 形に変化するものと仮定すると,

$\lg \overline{\mathrm{S}}_{\mathrm{N}}=\lg \overline{\mathrm{S}}_{3}+(\lg \mathrm{N}-3)\left(\lg \overline{\mathrm{S}}_{0}-\lg \overline{\mathrm{S}}_{3}\right) / 4$ 有限寿命のときのせん断疲れ強さ $\mathrm{S}_{\mathrm{N}}\left(\overline{\mathrm{S}}_{\mathrm{N}}, \xi_{\mathrm{SN}}\right)$ が求ま る。

なお， $\mathrm{N} \geq 10^{7}$ に対しては，

$\mathrm{S}_{\mathrm{N}} \approx \mathrm{S}_{0} \cdots$

以上のせん断疲れ強さ $\mathrm{S}_{\mathrm{N}}$ は両振り疲れ強さであるが, ばねの痩労は普通非対称繰返し応力によって生ずるの でGoodman 限度線図(図 3 ) により示される。

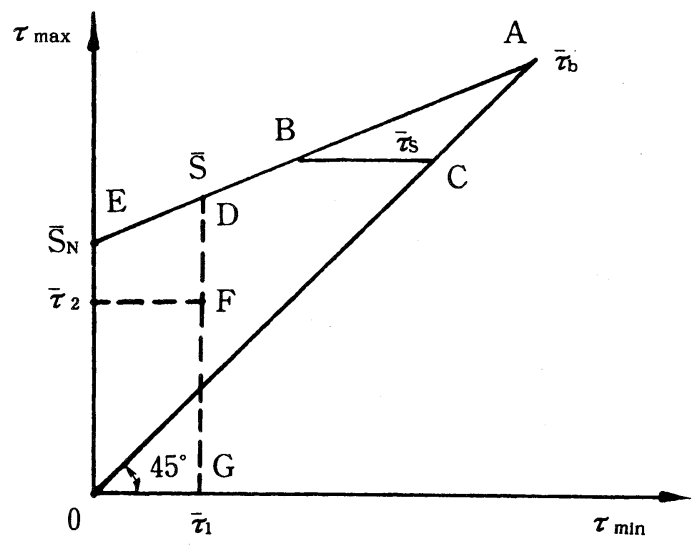

図 3 Goodman 限度線図

2.4.3 Goodman 限度線困のかき方

a ) $\tau_{\min }$ を横座標, $\tau_{\max }$ を縦座標とする。 $45^{\circ}$ の直線 を引き，直線の上に $\mathrm{A}\left(\bar{\tau}_{\mathrm{b}}, \bar{\tau}_{\mathrm{b}}\right)$ を取る。材料のせ ん断強さの平均値 $\bar{\tau}_{\mathrm{b}}$ は

$$
\left.\begin{array}{rll}
\mathrm{C} \leq 4 & \text { なら } & \bar{\tau}_{\mathrm{b}}=0.8 \bar{\sigma}_{\mathrm{b}} \\
4<\mathrm{C} \leq 6 & \text { なら } & \bar{\tau}_{\mathrm{b}}=0.7 \bar{\sigma}_{\mathrm{b}} \\
\mathrm{C}>6 & \text { なら } & \bar{\tau}_{\mathrm{b}}=0.6 \bar{\sigma}_{\mathrm{b}}
\end{array}\right\} \text { にとる。 }
$$

b) 縦軸の上に点 $\mathrm{E}\left(\mathrm{O}, \mathrm{S}_{\mathrm{N}}\right)$ を取り, 線 $\mathrm{AE}$ を引く。

c ) 縦座標がねじり弾性限度の平均值 $\bar{\tau}_{\mathrm{S}}$ もつ水平 線 $\mathrm{BC}$ をく。

ただし,

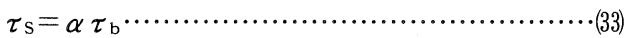

$$
\begin{aligned}
& \alpha \sim \mathrm{N}(0.9,0.03)
\end{aligned}
$$

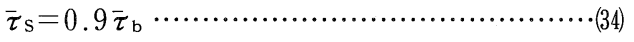

$$
\begin{aligned}
& \xi_{\tau \mathrm{s}}=\left[\bar{\tau}_{\mathrm{b}}^{2} \bar{\xi}_{\alpha}^{2}+\bar{\alpha}^{2} \bar{\xi}_{\tau \mathrm{b}}^{2}\right]^{1 / 2} \ldots \ldots \ldots \ldots \ldots \ldots \ldots \ldots \ldots(35)
\end{aligned}
$$$$
\text { とする。 }
$$

式中, $\xi_{\tau \mathrm{s}} \approx 0.054 \bar{\tau}_{\mathrm{b}}$

(1) $\tau_{\min }$ が一定の場合

ばねの使用応力 $\tau_{1}$ と $\tau_{2}$ が既知で, 疲れ限度線図は 
四 3 に示すものとする。 $\mathrm{FG}$ の延長線と $\mathrm{BE}$ とが $\mathrm{D}$ 点 で相交われば，使用応力の限度の応力 $\mathrm{S}_{\mathrm{m}}$ およびその 变動係数 $\mathrm{V}_{\mathrm{sm}}$ は

$$
\begin{aligned}
& \overline{\mathrm{S}}_{\mathrm{m}}=\bar{\tau}_{1}\left(\bar{\tau}_{\mathrm{b}}-\overline{\mathrm{S}}_{\mathrm{N}}\right) / \bar{\tau}_{\mathrm{b}}+\overline{\mathrm{S}}_{\mathrm{N}} \\
& \xi_{\mathrm{Sm}}=\mathrm{V}_{\mathrm{S}_{\mathrm{m}} \overline{\mathrm{S}}_{\mathrm{m}}} \ldots \ldots \ldots \ldots \ldots \ldots \ldots \ldots \ldots \ldots \ldots
\end{aligned}
$$

(38)

$\mathrm{FG}$ の延長線と $\mathrm{BC}$ が $\mathrm{AE}$ 上で相交われば，

$$
\begin{aligned}
& \overline{\mathrm{S}}_{\mathrm{m}}=\bar{\tau}_{\mathrm{s}} \\
& \xi_{\mathrm{Sm}}=\bar{\xi}_{\tau \mathrm{s}}
\end{aligned}
$$

となる。

(2) $\mathrm{r}=\tau_{\min } / \tau_{\max }$ が一定の場合

$\mathrm{r}=\tau_{\min } / \tau_{\max }$ は繰返し特性である。既知のばねの使 用応力が $\tau_{\min }$ と $\tau_{\max }$ で， $\mathrm{r}=\tau_{\min } / \tau_{\max }=$ 一定の場合に は直線 $\mathrm{OF}$ と $\mathrm{BE}$ あるいは $\mathrm{BC}$ の交点は使用応力の限 度応力 $\mathrm{S}_{\mathrm{m}}$ となる。(図 4 )

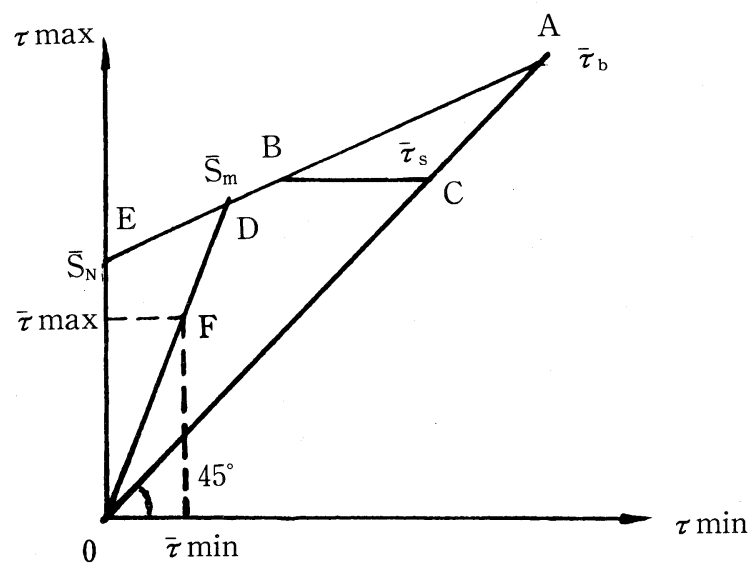

図 4 r が定数の場合の Goodman 限度線図

$\mathrm{OF}$ と $\mathrm{BE}$ が相交われば， $\overline{\mathrm{S}}_{\mathrm{m}}$ とその変動係数 $\mathrm{V}_{\mathrm{Sm}}$ は，

$$
\overline{\mathrm{S}}_{\mathrm{m}}=\overline{\mathrm{S}}_{\mathrm{N}} \bar{\tau}_{\mathrm{b}} /\left[\bar{\tau}_{\mathrm{b}}-\mathrm{r}\left(\bar{\tau}_{\mathrm{b}}-\overline{\mathrm{S}}_{\mathrm{N}}\right)\right]
$$

$\xi_{\mathrm{sm}}=\mathrm{Vs}_{\mathrm{m}} \overline{\mathrm{S}}_{\mathrm{m}}$

また，OF と BC が相交われば，

$$
\overline{\mathrm{S}}_{\mathrm{m}}=\bar{\tau}_{\mathrm{s}}
$$

$\xi_{\mathrm{Sm}}=\xi_{\tau \mathrm{s}}$

となる。

2.4.4 信頼度の計算

$$
\mathrm{R}=(1 / \sqrt{2 \pi}) \int_{\mathrm{Z}}^{\infty} \mathrm{e}^{-\mathrm{Z}^{2} / 2} \mathrm{dz}
$$

式中，積分範囲の下限は

$$
Z=\left(\overline{\mathrm{S}}_{\mathrm{m}}-\bar{\tau}_{\max }\right) /\left[\xi_{\mathrm{sm}}^{2}+\xi_{\tau}^{2}\right]^{1 / 2}
$$
となる。

\section{3. 信頼性設計の例}

例 2 イギリス規格 BS 4100 エンジン弁ばね用オイ ルテンパー線で製造され，ばね仕様が表 1 に示される ばねの信頼性設計の例を示す。すなわち, 以下の諸量を求める。

（1）普通工程のときの信頼度 $\mathrm{R}\left(\mathrm{N}=10^{6}\right)$

(2) ショットピーニングとホットセッチングを施した
時の信頼度 $\mathrm{R}\left(\mathrm{N} \geq 10^{7}\right)$

解：まず，せん断応力の平均值と標準偏差を求める。 式 ( 3 ) 上り,

$$
\begin{aligned}
& \bar{\tau}_{1}=286 \mathrm{~N} / \mathrm{mm}^{2} \\
& \bar{\tau}_{2}=630 \mathrm{~N} / \mathrm{mm}^{2}
\end{aligned}
$$

表 1 ばねの仕様

\begin{tabular}{|c|c|c|}
\hline 項 目 & 平 均 值 & 標準偏差 \\
\hline $\mathrm{d}$ & $3.55 \mathrm{~mm}$ & 0.01 \\
\hline $\mathrm{D}$ & $24.5 \mathrm{~mm}$ & 0.08 \\
\hline $\mathrm{n}$ & $5 \quad$ 巻 & 0.07 \\
\hline $\mathrm{P}_{1}$ & $169.54 \mathrm{~N}$ & 2.83 \\
\hline $\mathrm{P}_{2}$ & $373.38 \mathrm{~N}$ & 6.22 \\
\hline $\mathrm{G}$ & $77200 \mathrm{~N} / \mathrm{mm}^{2}$ & 1544 \\
\hline$\sigma_{\mathrm{b}}$ & $1667 \mathrm{~N} / \mathrm{mm}^{2}$ & 83.4 \\
\hline
\end{tabular}

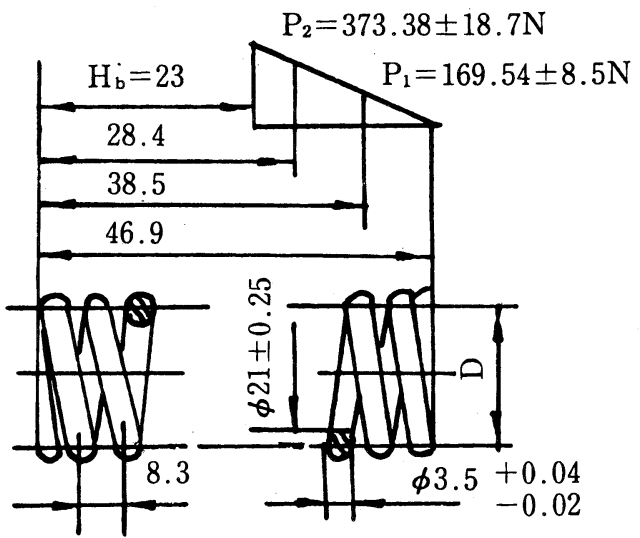

図 5 ばねの寸法と荷重特性

式( 7 ), (8), (9)より,

$$
\begin{aligned}
& \partial \tau_{2} / \partial \mathrm{d}=-21.57 \\
& \partial \tau_{2} / \partial \mathrm{D}=21.71
\end{aligned}
$$$$
\partial \tau_{2} / \partial \mathrm{P}=1.765
$$

表 1 より

$\xi_{\mathrm{d}}=0.01, \xi_{\mathrm{D}}=0.08, \xi_{\mathrm{P}}=6.22$ であり, これらよ $\eta$,

$$
\xi_{\tau 2}=1.12 \text { となる。 }
$$

\section{1 普通工程のときの信頼度 $\mathrm{R}\left(\mathrm{N}=10^{6}\right)$}

$\mathrm{C}=\mathrm{D} / \mathrm{d}=24.5 / 3.5=7$

$\beta \sim \mathrm{N}(0.54,0.02)$

$\overline{\mathrm{S}}_{3}=0.54 \bar{\sigma}_{\mathrm{b}}=900 \mathrm{~N} / \mathrm{mm}^{2}$

式(24)より， $\xi_{\sigma \mathrm{b}} \approx 0.05 \bar{\sigma}_{\mathrm{b}}$

式(23)より, 


$$
\begin{aligned}
\xi_{\mathrm{s} 3} & =\left[\bar{\sigma}_{\mathrm{b}}^{2} \xi_{\beta}^{2}+\bar{\beta}^{2} \xi_{\sigma \mathrm{b}}^{2}\right]^{1 / 2} \\
& =\left[1667^{2} \times 0.02^{2}+0.54^{2} \times(0.05 \times 1667)^{2}\right]^{1 / 2} \\
& =56 \\
\mathrm{~V}_{\mathrm{s} 3} & =\xi_{\mathrm{s} 3} / \overline{\mathrm{S}}_{3}=56 / 900=0.0622
\end{aligned}
$$

図 2 を参照して, $\mathrm{K}_{\mathrm{f}}=0.88$

普通工程のとき, $\mathrm{K}_{\mathrm{e}}=1$

式(26)より,

$$
\begin{aligned}
& =0.3 \mathrm{~K}_{\mathrm{f}} \cdot \mathrm{K}_{\mathrm{e}} \cdot \bar{\sigma}_{\mathrm{b}} \\
\overline{\mathrm{S}}_{0} & =0.3 \times 0.88 \times 1 \times 1667 \\
& =440\left(\mathrm{~N} / \mathrm{mm}^{2}\right)
\end{aligned}
$$

式(28)より, $\xi_{\mathrm{s} 0}=0.05 \overline{\mathrm{S}}_{0}=22$

$$
\mathrm{V}_{\mathrm{s} 0}=0.05
$$

式(30)より,

$$
\begin{aligned}
\mathrm{V}_{\mathrm{s}}= & \mathrm{V}_{\mathrm{s} 3}+(\lg \mathrm{N}-3)\left(\mathrm{V}_{\mathrm{s} 0}-\mathrm{V}_{\mathrm{s} 3}\right) / 4 \\
& =0.0622+\left(\lg 10^{6}-3\right)(0.05-0.0622) / 4 \\
& =0.053
\end{aligned}
$$

式(31)より,

$$
\begin{aligned}
\lg \overline{\mathrm{S}}_{\mathrm{N}} & =\lg \overline{\mathrm{S}}_{3}+(\lg \mathrm{N}-3)\left(\lg \overline{\mathrm{S}}_{0}-\lg \overline{\mathrm{S}}_{3}\right) / 4 \\
& =\lg 900+(6-3)(\lg 400-\lg 900) / 4 \\
& =2.69 \\
\therefore \overline{\mathrm{S}}_{\mathrm{N}} & =490 \mathrm{~N} / \mathrm{mm}^{2} \\
\xi_{\mathrm{SN}} & =\mathrm{V}_{\mathrm{S}} \overline{\mathrm{S}}_{\mathrm{N}}=0.053 \times 490=25.97
\end{aligned}
$$

ばねの負荷状況として, 応力比 $\mathrm{r}$ が定数であると仮定 すると, Goodman 限度線図は図 4の様になる。

$$
\begin{aligned}
& \mathrm{r}=286 / 636=0.454 \\
& \bar{\tau}_{\mathrm{b}}=0.6 \bar{\sigma}_{\mathrm{b}}=1000 \mathrm{~N} / \mathrm{mm}^{2} \\
& \bar{\tau}_{\mathrm{S}}=0.9 \bar{\tau}_{\mathrm{b}}=900 \mathrm{~N} / \mathrm{mm}^{2}
\end{aligned}
$$

式(41)より,

$$
\begin{aligned}
\overline{\mathrm{S}}_{\mathrm{Sm}} & =490 \times 1000 /[1000-0.454(1000-490)] \\
& =637,6 \\
\xi_{\mathrm{m}} & =\mathrm{V}_{\mathrm{s}} \overline{\mathrm{S}}_{\mathrm{m}}=0.053 \times 637.6=33.8 \\
\text { 式 } & (44) \text { より }, \\
Z & =(637.6-630) /\left(33.8^{2}+11.12^{2}\right)^{1 / 2} \\
& =0.214
\end{aligned}
$$

標準累積正規分布表 ${ }^{4)}$ より，

$$
\mathrm{R}\left(\mathrm{N}=10^{6}\right)=0.5948
$$

したがって，普通工程が採用された場合には明らかに， 信頼度の規定を達成しない。

\section{2 ショットピーニングとホットセッチングを}

\section{施した場合の信頼度 $R\left(N \geq 10^{7}\right)$}

ショットピーニングとホットセッチングを施した場 合, $\mathrm{K}_{\mathrm{e}}=1.4$

$$
\begin{aligned}
\overline{\mathrm{S}}_{0}= & 0.3 \times 0.88 \times 1.4 \times 1667 \\
& =616.12\left(\mathrm{~N} / \mathrm{mm}^{2}\right) \\
\overline{\mathrm{S}}_{\mathrm{m}}= & 616.12 \times 1000 /[1000-0.454(1000-616.12)] \\
= & 746.1\left(\mathrm{~N} / \mathrm{mm}^{2}\right) \\
\xi_{\mathrm{sm}} & =\mathrm{V}_{\mathrm{s} 0} \overline{\mathrm{S}}_{\mathrm{m}}=0.05 \times 746.1=37.3
\end{aligned}
$$

$$
\begin{aligned}
& \mathrm{Z}=(746.1-630) /\left(37.3^{2}+11.12^{2}\right)^{1 / 2} \\
& \quad=2.98 \\
& \mathrm{R}\left(\mathrm{N} \geq 10^{7}\right) \leq 0.998
\end{aligned}
$$

したがって, ショットピーニングとホットセッチング を施した場合には明らかに，信頼度の規定を達成する。

\section{4. 結 言}

以上, 信頼性工学の理論にもとづく圧縮コイルばね の信頼性設計の手順を示し，設計公式を導いた。

また，エンジン用弁ばねを例に信頼性設計法を具体 的に示し，製造工程の違いがばねの信頼度に及ぼす影 響を定量的に論じた。その結果, 従来ほとんど知られ ていなかった「圧縮コイルばねの信頼性設計」の意義 が明らかになった。

\section{参考文 献}

1) Haugen, E. B., "Probabilistic Mechanical Design”, (1980)，汪一麟ほか中国語訳，(1985)，機 械工業出版社。

2 ) 牟致忠, 機械可靠性設計(機械の信頼性設計)， 9 -93，（1986），上海工業大学.

3 ) 張英会, 螺旋弾簧可靠性研究報告 (コイルばねの信 頼性研究報告), III-33, (1988), 北京科技大学.

4 ) Hald,A., "Statistical Tables and Formulas" (1952), John Wiley \& Sons. 